\title{
PERLINDUNGAN HUKUM BAGI PEKERJA TAMBANG GALIAN C DALAM PERSPEKTIF PENGUPAHAN DAN KESEJAHTERAAN PEKERJA DI WILAYAH PROVINSI JAWA BARAT
}

\section{LEGAL PROTECTION FOR TYPE C MINING WORKERS IN THE PERSPECTIVE OF IT WAGING AND WELFARE IN WEST JAVA PROVINCE AREA}

\section{R. Pepen Rustam Effendi dan Martin Roestamy}

\author{
Program Studi Ilmu Hukum Sekolah Pascasarjana \\ Universitas Djuanda Bogor \\ Jl. Tol Ciawi No. 1, Kotak Pos 35, Bogor 16720. \\ Korespondensi : R. Pepen Rustam E, Telp. - \\ e-mail : pepenrustamsh@gmail.com
}

Jurnal Living Law, Vol. 10, No.

2 , 2018 hlm. 104113

\begin{abstract}
Legal protection for Site C Miners is element that is implied in Article 27 of Undang-Undang Dasar 1945 where it is written that every citizen is equal in the eye of the law and have to obey the law. It also says that every citizen has rights for job and welfare in the name of humanity. The purposes of the research in Site C Mine in West Bandung Regency, Cianjur, Bogor Regency, West Java, are only to find out about Law Protection of Waging System and Welfare and whether the company of the Site $C$ Mine follows the rule of minimum wage that is regulated in West Java region. The results of the research are for the miners of Site C Mine in 3 (three) regencies of West Java, the company already follows the rules and the Labor Law. However, according to research, there are workers who already work for 1 (one) year and get 12 (twelve) days of annual leave without cutting the wage. This thing is only applied to permanent workers, but not to outsource workers even though they already work for the company for years, and still be given welfare every year.
\end{abstract}

Keywords : Legal Protection, Miners, Waging.

\begin{abstract}
Abstrak : Perlindungan Hukum bagi Pekerja Tambang Galian C adalah merupakan unsur-unsur yang terkandung didalam Pasal 27 Undang-undang Dasar 1945. Dimana Warga Negara bersamaan kedudukkannya didalam hukum dan wajib menjunjung hukum, serta setiap warga Negara berhak atas pekerjaan dan penghidupan yang layak bagi kemanusiaan. Tujuan penelitian dilokasi Tambang Galian C yang berlokasi diwilayah Kabupaten Bandung Barat, Cianjur dan Kabupaten Bogor Jawa Barat, hanya meneliti mengenai Perlindungan Hukum tentang Pengupahan dan kesejahteraannya saja, apakah Perusahaan yang bergerak dalam Usaha Pertambangan Galian C sudah memenuhi unsur-unsur yang terkandung didalam Undang-undang No. 13 tahun 2003 mengenai ketenagakerjaan dan apakah perusahaan Galian C tersebut sudah mengikuti aturan Upah minimum yang berlaku diwilayah Jawa Barat. Atas dasar hasil dalam penelitian bagi Pekerja Tambang Galian C yang terdapat di 3 (tiga) Kabupaten wilayah Jawa Barat, Perusahaan secara seksama telah mengikuti Peraturan-peraturan secara Hukum Ketenagakerjaan. Namun ternyata dilapangan pekerjaan ada Pekerja yang sudah lama bekerja selama 1 (satu) tahun dapat Cuti 12 (dua belas ) hari dan Upah tetap tidak dipotong, hal ini hanya berlaku untuk pekerja tetap saja dan tidak berlaku bagi pekerja harian walaupun bekerja sudah bertahun-tahun, akan tetap diberikan Kesejahteraan setiap tahunnya.
\end{abstract}

Kata Kunci : Perlindungan Hukum, Pekerja Tambang, Pengupahan. 


\section{PENDAHULUAN}

Pertambangan adalah salah satu jenis kegiatan yang melakukan ekstraksi mineral dan bahan tambang lainnya dari dalam bumi. Penambangan adalah proses pengambilan material yang dapat diekstraksi dari dalam bumi. Tambang adalah tempat terjadinya kegiatan penambangan. Manusia merupakan unsur yang tak dapat dipisahkan dari geografi, sebab dalam geografi mempelajari manusia sebagai subyek yang menempati dan memanfaatkan bumi ini secara timbal balik untuk berkembang lebih baik dan tidak hanya pada hubungan manusia dengan manusia melainkan juga manusia dengan unsur fisiknya.

Batas ruang lingkup berlakunya Hukum Ketenagakerjaan menurut teori "Gebiedsleer" yang dikemukakan oleh JHA. Logemann, demikian juga mengenai pemahaman paradigma hukum ketenagakerjaan perlu diuraikan cara pandang berbagai permasalahan hukum ketenagakerjaan ditinjau dari ilmu kaidah hukum, ilmu pengertian, dan filsafat hukum ketenagakerjaan.

Menurut Imam Soepomo, Hukum ketenagakerjaan adalah himpunan Peraturan, baik tertulis maupun tidak tertulis, yang berkenaan dengan suatu kejadian dimana seseorang bekerja pada orang lain, dengan menerima upah. ). bahwa dari pengertian tersebut Hukum ketenagakerjaan masih belum menyeluruh karena masing-masing definisi belum menjawab permasalahan yang ada dalam Hukum ketenagakerjaan karena ruang lingkup masing-masing definisi masih terbatas.

Geografi adalah ilmu yang mempelajari hubungan gejala di bumi yang menyangkut fisik maupun makhluk hidup beserta permasalahannya melalui pendekatan keruangan, ekologi dan kewilayahan untuk kepentingan proses dan keberhasilan pembangunan. Manusia membutuhkan macam-macam kebutuhan, salah satu kebutuhan pokok manusia adalah masalah sumber mata pencaharian. Masalah lingkungan seperti pencemaran, kerusakan dan bencana dari tahun ke tahun masih terus berlangsung dan semakin luas. Kondisi tersebut tidak hanya menyebabkan menurunnya kualitas lingkungan tetapi juga memberikan dampak yang sangat serius bagi kesehatan dan jiwa manusia. Buruknya kualitas lingkungan, di antaranya disebabkan antara lain oleh pertambahan penduduk yang semakin pesat dan meningkatnya kebutuhan akan sumber daya.

Setelah Undang-Undang Nomor 11 Tahun 1967 tentang Ketentuan-Ketentuan Pokok Pertambangan diganti dengan Undang-Undang Republik Indonesia Nomor 4 tahun 2009 Tentang Pertambangan Mineral Dan Batubara, banyak hal terjadi di Daerah khususnya dalam pertambangan "besar" atau pertambangan "kecil" /rakyat. Berdasarkan Pasal 175, Undang-Undang ini mulai berlaku pada tanggal diundangkan. Dan Disahkan di Jakarta pada tanggal 12 Januari 2009 oleh Presiden Republik Indonesia, DR. H. Susilo Bambang Yudhoyono. Kemudian timbul pertanyaan, bagaimana dengan Peraturan pelaksanaannya. Bahwasannya Pasal 174 UU 4/2009 ini menyatakan Peraturan pelaksanaan Undang-Undang ini harus telah ditetapkan dalam waktu 1 (satu) tahun sejak UndangUndang ini diundangkan. Kemudian Peraturan Pelaksanaannya dalam Undangundang tersebut di implementasikan dalam Peraturan Pemerintah (PP) dan Peraturan Daerah, diantaranya:

a. Peraturan Pemerintah Republik Indonesia Nomor 22 Tahun 2010 tentang Wilayah Pertambangan.

b. Peraturan Pemerintah Republik Indonesia Nomor 23 Tahun 2010 tentang Pelaksanaan Kegiatan Usaha Pertambangan Mineral Dan Batubara.

c. Peraturan Pemerintah Republik Indonesia Nomor 55 Tahun 2010 tentang Pembinaan Dan Pengawasan Penyelenggaraan Pengelolaan Usaha Pertambangan Mineral Dan Batubara. 
Peraturan pelaksanaan dari PP ini telah terbit diantaranya Peraturan Menteri Energi dan Sumber Daya Mineral Republik Indonesia Nomor: 24 Tahun 2012 tentang Perubahan Atas Peraturan Menteri Energi dan Sumber Daya Mineral Nomor 28 Tahun 2009 tentang Penyelenggaraan Usaha Jasa Pertambangan Mineral dan Batubara. Disisi lain, UU 4/2009 tentang ini juga mengamanahkan kepada Pemerintah Daerah untuk membuat Perda ${ }^{1}$.

\section{METODE PENELITIAN}

Bahwa tinjauan penulis didalam penelitian ini bersifat Empiris. Yaitu berdasarkan kepada pengalaman yang terjadi di lingkungan Masyarakat, khususnya di lingkungan Areal lokasi Perusahaan Galian (C) yang berada diwilayah Kabupaten Bandung Barat, Kabupaten Cianjur dan Kabupaten Bogor, Provinsi Jawa Barat. Penulis mengkaji dalam penelitiannya berdasarkan perspektif hukum Ketenagakerjaan yang berlaku dalam menunjang kesejahteraan bagi buruh / pekerja di lingkungan Galian (C), sehingga tercapainya suatu keadilan bagi para pekerja Galian (C) di wilayah Provinsi Jawa Barat, bahwa penelitian hukum secara Empiris ini dilakukan untuk mengetahui sampai sejauh mana Peraturan hukum Ketenagakerjaan berjalan didalam Perusahaan Galian (C), dengan menghubungkan referensi penelitiannya berdasarkan pengumpulan data-data, dan apakah telah sesuai dengan ketetapan UMK yang berlaku di Jawa Barat. Serta fakta-fakta yang berkaitan dengan aturan hukum Ketenagakerjaan, kemudian dianalisis secara kualitatif. ${ }^{2}$.

Jenis Penelitian yang dilakukan dengan cara Normatif Empiris/Applied law research, dan penelitian ini merupakan bersifat Deskriptif Analisis. Sumber data yang digunakan dalam penelitian ini,

\footnotetext{
1 Pasal 26, 72, dan 143.

2 Muhammad Taufiq, Keadilan Substansi Memangkas Rantai Birokrasi Hukum, Bab III Metode Penelitian (Yogyakarta, Pustaka Pelajar, 2014), Hlm. 149.
}

adalah data sekunder (secondary data) dan data primer (primary data).

Adapun Teknik pengumpulan data yang digunakan pada penelitian ini yaitu melalui studi kepustakaan dan wawancara (interview) kepada pihak-pihak terkait.

\section{PEMBAHASAN}

\section{A. PENGELOLAAN GOLONGAN GALIAN C}

Bahan Galian Golongan C adalah bahan galian yang tidak termasuk dalam katagori bahan galian strategis (A), dan golongan bahan galian vital (B), yang hal ini diatur didalam PP Nomor 27 Tahun 1980. Sebelum diatur didalam PP Nomor 27 Tahun 1980, penggolongan bahan-bahan Galian Golongan C diatur didalam PP th 1964, dan telah tidak sesuai lagi dengan keadaan masyarakat apabila dihubungkan dengan kemajuan teknologi dibidang pertambangan dan perkembangan kegunaan bahan-bahan galian.

Maka untuk itu dipandang perlu untuk mengatur kembali penggolongan bahanbahan galian Golongan $\mathrm{C}$ tersebut dengan mengadakan penggolongan baru yang didasarkan pada terdapatnya sebagai bahan-bahan galian yang dalam penggunaannya sebagai bahan industri, yang mempunyai nilai strategis atau nilai ekonomi bagi negara dan bangsa dalam pemerataan kesempatan untuk berusaha serta penyebaran pembangunan pertambangan untuk wilayah seluruh Indonesia. Di mana pengelolaan tersebut disesuaikan dengan Pasal 33 Ayat (3) UUD 1945 dan UU No. 11 Tahun 1967 tentang ketentuan-ketentuan pokok pertambangan (LN 1967 No. 22). Dimana dasar-dasar penggolongan bahan-bahan galian berpegang pada :

a. Nilai strategis/ekonomis bahan galian terhadap Negara.

b. Terdapatnya suatu bahan galian dalam alam.

c. Penggunaan bahan galian bagi industri.

d. Pengaruhnya terhadap kehidupan rakyat banyak. 
e. Pemberian kesempatan pengembangan bagi Para Pengusaha.

f. Penyebaran pembagian di Daerahdaerah.

Penggolongan bahan-bahan galian yaitu :

a) Bahan galian strategis (A) artinya digunakan untuk bertahan/keamanan serta perekonomian Negara;

b) Bahan galian Vital (B) artinya dapat menjamin hayat hidup orang banyak;

c) Bahan galian yang tidak termasuk bahan galian strategis (A) dan bahan galian Vital (B) berarti sifatnya tidak langsung memerlukan pasaran yang bersifat Internasional.

Maka dengan adanya kesemuanya itu Pemerintah Daerah membuat Peraturan, dan Peraturan tersebut dikeluarkan oleh Propinsi. Yang mana perizinan galian C yang berada diwilayah Kabupaten Bandung barat, Bogor dan Cianjur, dibawah Peraturan-Peraturan Propinsi Jawa barat No. 3 tahun 1983. Tentang usaha-usaha pertambangan bahan golongan galian $\mathrm{C}$ serta peraturan dalam pelaksanaannya yaitu No. 540/SK/717/BINPROD/1985.

\section{B. KEGUNAAN BAHAN GALIAN GOLONGAN C}

Bahwa bahan-bahan Galian Golongan C sangat diperlukan untuk kepentingan sebagai bahan pokok dalam pembangunan. Galian Golongan C yang sering digunakan oleh Masyarakat maupun oleh Pemerintah terutama untuk kepentingan pembangunan gedung, pembuatan jalan, bendungan, parit-parit, dan sebagainya.

Pertambangan di bidang galian golongan $\mathrm{C}$ selain produksinya untuk kepentingan pembangunan, juga dampaknya sangat besar sekali untuk menyerap tenaga kerja dibidang pembangunan, di mana pembangunan secara umum di desa maupun di kota-kota bahan pokoknya adalah Galian Golongan C. Maka dengan adanya Galian Golongan C sehingga dapat membantu dan meringankan beban Pemerintah dalam membina Ketenagakerjaan dibidang pekerja bangunan.

\section{GALIAN GOLONGAN C MENYERAP TENAGA KERJA}

Bahwa dengan adanya Para Pengusaha yang bergerak dibidang Galian Golongan C Khususnya di Kabupaten Bandung Barat, Cianjur dan Bogor Propinsi Jawa Barat, hal tersebut merupakan andil para pengusaha untuk menentaskan kemiskinan dan mengurangi banyaknya pengangguran ditingkat Masyarakat menengah kebawah, maka hal tersebut secara tidak langsung membantu Pemerintah untuk mengurangi tingkat pengangguran. Tentunya Pihak Perusahaan dalam hal ini untuk melaksanakan kegiatan dalam usahanya sangat memerlukan para tenaga kerja dibidangnya, khususnya Ketenagakerjaan dibidang galian golongan $\mathrm{C}$.

Bahwa Para Pengusaha dibidang Galian Golongan C yang berada di Wilayah Kabupaten bandung Barat, Cianjur dan Bogor, sistim pengupahannya diatur oleh Undang-undang, sebagaimana tertera dalam Peraturan Ketenagakerjaan Undang-undang Republik Indonesia Nomor 13 tahun 2003, Undang-undang Republik Indonesia Nomor 21 tahun 2000 tentang Serikat Pekerja / Serikat Buruh, dan Undang-undang Republik Indonesia Nomor 2 tahun 2004, tentang Penyelesaian Perselisihan Hubungan Industrial.

\section{PERLINDUNGAN HUKUM BAGI PEKERJA TAMBANG GALIAN C DI JAWA BARAT.}

Bahwa hasil Penelitian Penulis terhadap Para Pengusaha Galian Golongan $C$ yang berada di Wilayah Kabupaten Bandung Barat, Cianjur dan Bogor, sistim dalam melaksanakan ketenagakerjaannya mengacu kepada UU RI No. 13 tahun 2003. Jo. UU RI No. 21 tahun 2000. Jo. UU RI No. 2 tahun 2004. Dan hasil penelitian tersebut bahwa Para Pengusaha tidak ada yang membayar Upah lebih rendah dari Upah Minimum. Sedangkan Upah Minimum 
Pekerja ( UMP ) yang berlaku di Propinsi Jawa Barat saat sekarang sebesar Rp. 3.204.551,- ( Tiga juta dua ratus empat ribu lima ratus lima puluh satu rupiah ). Per bulannya. Bahkan Upah bagi Para Pekerja Galian Golongan $C$ berikut tunjangan yang lainnya diatas UMP yang berlaku di Jawa Barat. Sehingga sistim Pengupahan dan kesejahteraan yang diberlakukan oleh Para Pengusaha Galian Golongan C sudah cukup baik, dan tidak ada perselisihan yang timbul didalam Galian Golongan C karena Upah. Bahkan bagi Pekerja yang sudah diatas lima tahun masa kerjanya, setiap bulan penghasilannya minimal sekitar Rp. 4.500.000,- ( Empat Juta lima ratus ribu rupiah ). ${ }^{3}$

\section{KESIMPULAN}

Berdasarkan uraian dari hasil Penelitian, Maka dapat diambil beberapa kesimpulan sebagai berikut:

1. Bahwa sistem pengupahan pada Perusahaan Tambang Galian C yang berada diwilayah Kabupaten Bandung Barat, Bogor dan Cianjur terhadap Para pekerjanya, yang dihubungkan dengan Undang-undang Ketenagakerjaan, sistim pengupahannya dalam Ketenagakerjaan telah sesuai dengan ketetapan UMK yang berlaku di Jawa Barat. Tata tertib tentang ketenagakerjaan sudah sesuai dengan peraturan yang tertera dalam UndangUndang Ketenagakerjaan. Bahkan ditinjau secara langsung keharmonisan antara pekerja dengan Pengusaha dapat terlihat dari sikap pekerja galian C terhadap majikannya secara timbal balik saling memenuhi kebutuhannya serta harga-menghargai dan hormatmenghormati pada pelaksanaan tata cara melakukan dalam pekerjaannya, walaupun dalam pengertian ini hanya sebagian kecil saja.

2. Dalam Perlindungan Hukum bagi Para Pekerja Tambang Galian C

3 Wawancara langsung dengan pekerja galian $\mathrm{C}$ wilayah Jawa Barat.
Berdasarkan penelitian masih terlihat diantara Majikan dengan Pekerjanya kurangnya pengetahuan terhadap ketentuan-ketentuan yang mengatur dalam hukum Ketenagakerjaan, namun demikian Perlindungan Hukum dan kesejahteraannya bagi para pekerja galian C Cukup baik, karena antara buruh dan majikan saling mematuhi peraturannya masing-masing. Dan bila terjadi musibah terhadap pekerja, maka semua biaya menjadi tanggung jawab Perusahaan.

3. Dari hasil penelitian yang telah dilaksanakan ternyata ada 2 (dua) katagori yang antara lain:

a. Mengerti dan melaksanakan arti hubungan Ketenagakerjaan. Artinya semua peraturan yang tertera dalam hukum ketenagakerjaan telah ditaatinya baik oleh pekerja maupun majikan.

b. Mengerti, namun tidak melaksanakannya. Artinya Masa pekerja yang sudah lewat 1 (satu) tahun, mendapat Cuti tahunan selama 12 (dua belas) hari, upah tetap tidak dipotong. Ternyata $\mathrm{Hal}$ ini hanya berlaku terhadap Para pekerja tetap saja. Dan tidak berlaku bagi pekerja harian, sekalipun pekerja harian tersebut masa kerjanya sudah bertahuntahun. Karena sistim pekerja harian pada galian $\mathrm{C}$, ada kerja ada upah jika tidak ada kerja maka tidak ada upah. Maka hal ini disebabkan oleh faktor kurangnya penunjang kearah itu, sehubungan telah lebih kuatnya adat kebiasaan yang diterapkan pada pekerja galian $\mathrm{C}$ tersebut.

4. Pekerja Galian C pada umumnya bukan tergolong kepada manusia yang berpendidikkan tinggi, melainkan dalam ilmu pengetahuannya sangat rendah sekali, karena dalam melaksanakan pekerjaan tidak memakai ilmu pemikiran secara ilmiah, 
melainkan yang diutamakan badan sehat dan bisa melakukan pekerjaan yang berat. Akan tetapi tidak semua pekerja galian $\mathrm{C}$ berpendapat demikian, yang tentunya hal apapun akan mereka patuhi sesuai dengan Peraturan dari pihak Pengusaha yang mereka ikuti. Sedang alasan yang lain bagi buruh galian $\mathrm{C}$ kebanyakan sehubungan dengan kebutuhan untuk memenuhi kehidupan dalam rumah tangganya. Selain faktor keadaan yang sangat mendesak. Mengingat sangat sulitnya mencari pekerjaan yang layak.

5. Bahwa di dalam Perusahaan Galian C menyangkut hubungan antara pekerja dan majikan sangat harmonis bahkan tentang kesejahteraannya pun Pengusaha Galian C tersebut sangat memperhatikan sekali terhadap Para pekerjanya bahkan sama sekali tidak pernah timbul permasalahan, Maka dengan adanya Pengusaha yang mengelola dalam Golongan Galian C ini, antara buruh dan majikan tidak ada permasalahan, akan tetapi permasalahan yang timbul selain dampak positif terhadap berbagai pihak, juga timbul dampak negatif dilain pihak, diantaranya perubahan polusi, tercemarnya terhadap aliran sungai, udara tercemar debu khususnya di Kabupaten Bandung Barat. Serta akibat penggalian dataran tentu menjadi rendah. Kemudian banyak sawah-sawah yang terlantar karena para petaninya berpindah haluan lebih senang bekerja pada Galian $\mathrm{C}$ dibandingkan dengan bertani. Hal tersebut dikarenakan penghasilannya jauh lebih untung bekerja di galian $\mathrm{C}$, sehingga akhirnya lahan petani ditinggalkan dan lahan penuh dengan alang-alang, kemudian menimbulkan ketidakserasian lagi.

\section{SARAN}

1. Bahwa atas dasar pengamatan yang telah dilaksanakan di lapangan, disarankan kepada Kantor Dinas Tenaga kerja Kabupaten Bandung barat, Kabupaten Bogor dan Kabupaten Cianjur khususnya, agar meningkatkan pelayanan yang lebih baik lagi kearah tercapainya tertib dalam melaksanakan UU sesuai dengan hukum Ketenagakerjaan, mengingat wilayah penelitian tersebut termasuk banyak pekerja yang belum memahami arti UU ketenagakerjaan. Bagi pekerja dan Pengusaha yang belum sadar akan pentingnya tentang arti dari pada hubungan kerja dan Peraturanperaturan UU lainnya dalam Ketenagakerjaan. Agar dapat meningkatkan kesadaran masingmasing para pihak demi untuk tercapainya kerukunan dan sukses antara buruh dan Pengusaha.

2. Agar terpeliharanya pemanfaatan sumber daya alam termasuk didalamnya disarankan kegiatan penggalian golongan $\mathrm{C}$, perlu adanya pengawasan secara terpadu oleh Pemerintah Daerah, sehingga dalam penggalian sumber daya alam tetap sesuai dengan pola dan cara yang serasi dan seimbang agar tidak merusak lingkungan hidup dialam sekitarnya. Dan disarankan bagi Pengusaha Galian C yang sudah selesai, mengingat bekas galian tanah menjadi keras, hendaknya tanah bekas galian tersebut agar digemburkan dan ditata kembali supaya bisa dimanfaatkan untuk pertanian dan perkebunan. 


\section{UCAPAN TERIMA KASIH}

\section{DAFTAR PUSTAKA}

Abdussalam. 2016. Hukum Ketenagakerjaan (Hukum Perburuhan). Jakarta: PTIK.

Aloysius Uwiyono. 2014. Asas-asas Hukum Perburuhan, Penerbit PT. Raja Grafindo Persada, Jakarta.

Arief, I. 2007. Perencanaan Tambang Total Sebagai Upaya Penyelesaian Persoalan Lingkungan Dunia Pertambangan, Universitas Samratulangi, Manado.

Asyhadie, Zaeni. 2007. Hukum Kerja : Hukum Ketenagakerjaan Bidang Hubungan Kerja. Raja Grafindo Persada. Jakarta.

Abraham Maslow. 1994. Motivation and Presonality. Harper \& Row, New York.

Aditya Bakti. 1981. Gunardi. Tom. Sistim Perekonomian Menurut Pancasila dan UUD 1945. CV. Angkasa Bandung.

Bertrand Russell. 1992. History of Western Philosophy London Macmillan. London.

Ceramah Emil Salim. 1986. Menteri Negara Kependudukan dan Lingkungan Hidup. Seminar sehari. Unpak Bogor.

Fuady, Munir. Hukum Bisnis dalam teori dan Praktek.

Georg Simmel dan Rijadi Soeprapto. 2002. Interaksionesme Simbolik (Perspektif Sosiologi Modern), Pustaka Pelajar, Yogyakarta.

Hadiwardojo R.K. 1981. Diktat Hukum Ketenagakerjaan. Fakultas Hukum Unpad Bandung.

Hadiwardojo. 1980. Undang-undang Hukum Perburuhan, Jakarta. Halaman 146.

H.R. Abdussalam, Adri Desasfuryanto. 2016. Hukum Ketenagakerjaan, Penerbit PTIK, Jakarta.

Hardjasoemantri. Koesnadi. Hukum Tata Lingkungan. Edisi keenam. Yayasan Gajah Mada University.

Iman Soepomo. 1995. Hukum Perburuhan Bidang Hubungan Kerja. Djambatan, Jakarta .

Iman Soepomo. Pengantar Hukum Perburuhan.

Iman Soepomo. 1975. Hukum Perburuhan Bidang Hubungan kerja, Cetakan Pertama.

Iman Soepomo. 1980. Hukum Perburuhan Bidang Hubungan Kerja, Penerbit Djambatan, Jakarta.

Indonesia. Pancasila dan Undang-Undang Dasar Republik Indonesia 1945, 
Indonesia. Undang-undang Dasar Sementara tahun 1950.

Indonesia. Undang-undang No. 22 / 1957. Tentang Penyelesaian Perselisihan Perburuhan.

Indonesia. Undang-undang RI Nomor: 11 Tahun 1967 tentang Ketentuan-ketentuan Pokok Pertambangan.

Indonesia. Undang-undang RI Nomor: 3 Tahun 1982 tentang Wajib Daftar Perusahaan.

Indonesia. Undang-undang RI Nomor: 13 Tahun 2003 tentang Ketenagakerjaan.

Indonesia. Undang-undang RI Nomor: 40 Tahun 2007 tentang Perseroan Terbatas.

Indonesia. Undang-undang RI Nomor: 12 Tahun 2008 tentang Perubahan Kedua Atas UU Nomor 32 Tahun 2004 Tentang Pemerintahan Daerah.

Indonesia. Undang-undang RI Nomor 20 Tahun 2008 Tentang Usaha Mikro, Kecil, dan Menengah.

Indonesia. Undang-undang RI Nomor 32 Tahun 2009 Tentang Perlindungan dan Pengelolaan Lingkungan Hidup.

Indonesia. Undang-undang No. 4/2009. Tentang Pertambangan.

Indonesia. Tap. MPR.RI. No. II/MPR/1983. GBHN, Tentang Tenaga Kerja.

Indonesia. Peraturan Pemerintah RI Nomor 38 Tahun 2007 tentang Pembagian Urusan Pemerintah antara Pemerintah, Pemerintah Daerah Provinsi, Pemerintah Daerah Kabupaten/Kota.

Indonesia. Peraturan Pemerintah RI Nomor 50 Tahun 2007 tentang Tata Cara Pelaksanaan Kerjasama Daerah.

Indonesia. Peraturan Pemerintah Republik Indonesia. Nomor 22 Tahun 2010. Tentang Wilayah Pertambangan.

Indonesia. Peraturan Pemerintah Republik Indonesia Nomor 78 Tahun 2015 tentang Pengupahan.

Indonesia. Keputusan Menteri Tenaga Kerja dan Transmigrasi Republik Indonesia tentang Waktu Kerja Lembur dan Upah Kerja Lembur. Permenakertrans No. 102 Tahun 2004.

Internet Google. Pendapat Rosco Pound, Senin 13-11-2017. Jam 16.00 Wib. www.slideshare.com., Teori Media dan Teori Kemasyarakatan. http://fh.unsri.ac.id/userfiles/2\%20Pengertian\%20dan\%20Asas-asas.pdf.

Irfan Abet. 2013. http://lovegeografi-geografiku.blogspot.com/2009/11/jenis-jenis-danpersebaran-sumber-daya.html.

Iskandar. 2008. Teknik Keberhasilan Reklamasi Dan Penutupan Tambang:Keberhasilan Reklamasi Lahan Bekas Tambang untuk Tujuan Revegetasi. Bogor: Fakultas Pertanian IPB. 
John Locke. 1993. Two Treatises of Government, New Edition (London, Everiman).

Karliansyah, M.R. 1991. Aspek Lingkungan dalam Amdal bidang Pertambangan. Pusat Pengembangan dan penerapan Amdal. Jakarta.

Koesnadi Hardjasoemantri. 1994. Hukum Tata Lingkungan, Edisi keenam, Cetakan kesebelas, Penerbit Gajah Mada University.

Lili Rasjidi dan Ira Thania Rasjidi. 2007. Dasar-dasar Filsafat dan Theori Hukum, PT. Citra Aditya Bakti. Bandung.

Majalah Hukum Nasional Nomor 2. 1995. Badan Pembinaan Hukum Nasional (BPHN), Rumusan Hasil Seminar Temu Kenal Cita Hukum dan Penerapan Asas-asas Hukum Nasional. http://industri.bisnis.com/read/20151123/12/494944/apindo-selainupah-pemerintah-harus-ikut-naikkan-kesejahteraan-buruh.

Martin Roestamy. 2015. Jurnal ilmiah Program Magister Ilmu Hukum, LIVING LAW, Penerbit Lembaga Penelitian dan Pengabdian kepada Masyarakat (LPPM) Universitas Djuanda Bogor.

Martin Roestamy, Endeh Suhartini, Aal Lukmanul Hakim, Ani Yumarni. 2015. Metode, Penelitian, Laporan, dan Penulisan Karya Ilmiah Hukum pada Fakultas Hukum, Universitas Djuanda Bogor.

Martin Roestamy. 2011. Konsep-konsep Hukum Kepemilikan Properti bagi Asing, Penerbit PT. Alumni Bandung.

Muhammad Taofiq. 2014. Keadilan Subtansial memangkas rantai Birokrasi Hukum, Cetakan I Oktober, Penerbit Pustaka Pelajar, Yogyakarta.

Muhammad Taofiq. 2016. Catatan Perkuliahan Metode Penelitian Hukum dan Literatur Penulisan Hukum (Bogor Universitas Djuanda Bogor, Program Pascasarjana ilmu Hukum).

Nollen, VH Prof. 1956. Arti dan luas perundang-undangan kerja, terjemahan Sridadi Yayasan kaussius, Semarang.

Panji Anoraga. 1992. Psikologi kerja. Rineka Cipta, Jakarta.

Pedoman Pelaksanaan Hubungan Industrial Pancasila (HIP), Cetakan kedua. 1987, Yayasan Tripartit Nasional tentang Jaminan Sosial dan Kesejahteraan Pekerja.

Prismi Warassih. 2005. Pranata Hukum Sebuah Telaah Sosiologi, Tulisan Guru Besar Sosiologi Hukum UNDIP Semarang. PT. Suryandaru Utama. Semarang.

Propinsi Jawa Barat. 2017. Dalam Penegasan Rapat Pleno, Dewan Pengupahan Jawa Barat, Untuk Wilayah Kabupaten / Kota.

Rahmawaty. 2002. Restorasi Lahan Bekas Tambang berdasarkan Kaidah Ekologi, Medan: Fakultas Pertanian, Universitas Sumatera Utara.

Redaksi Karya Anda. Kamus Internasional (Surabaya Karya Anda 1 th ) 
R. Subekti. 2003. Pokok-pokok Hukum Perdata, Cetakan XXXI, Penerbit PT. Intermasa, Jakarta.

R. Subekti dan Tjitrosudibio. Undang-undang Hukum Perdata, Cetakan keempat.

Seminar. 1974. HPP Sebagai Wahana Menuju Ketenangan Kerja Stabilitas Sosial Ekonomi Untuk Pembangunan Nasional. Desember.

Setiono. 2004. Rule of Law, disertasi S-2 Fakultas Hukum Universitas Sebelas Maret. Surakarta.

Subowo. 2011. Penambangan Sistem Terbuka Ramah Lingkungan Dan Upaya Reklamasi Pasca Tambang Untuk Memperbaiki Kualitas Sumberdaya 104 Lahan dan Hayati Tanah. Jurnal Sumberdaya Lahan.

Soerojo Wignyodipuro. Pengantar dan Azas-azas Hukum Adat.

Soeryono Soekamto. 1981. Pengantar Penelitian Hukum, UI.Press. Jakarta.

Thomas, Hobbes. 1985. Leviathan Middleessex England Penguin Books.

Thoga, Hutagalung. 1993. Peranan Hukum dan Keadilan Dalam Pembangunan Masyarakat yang sejahtera. CV. Armico. Bandung.

Wiryono, Prodjodikoro, Hubungan Perdata Tentang Persetujuan tertentu, Cetakan kedua.

Zainuddin, Ali. Sosiologi Hukum, Sinar Grafika, Jakarta. 2008.

Zainuddin, Ali Filsafat Hukum, Sinar Grafika. Jakarta. 2006.

2009. Metode Penelitian Hukum, Sinar Grafika. Jakarta.

2007. Sosiologi Hukum. Sinar Grafika. Jakarta. 